\title{
Effect of Machining Parameters and Optimization of Temperature Rise in Turning Operation of Aluminium-6061 Using RSM and Artificial Neural Network
}

\author{
Mahesh Gopal1* \\ 1 Department of Mechanical Engineering, College of Engineering and Technology, Wollega University, P. O. B. 395, Nekemte, \\ Ethiopia \\ * Corresponding author, e-mail: doctorgmahesh@wollegauniversity.edu.et
}

Received: 08 June 2020, Accepted: 26 November 2020, Published online: 22 February 2021

\begin{abstract}
The aim of this study is to determine the effect of the machining parameters and tool geometry. The turning operation is carried out as per the Design of Experiments (DoE) of Response Surface Methodology (RSM) to predict the temperature rise of aluminium-6061 as a cutting material and $\mathrm{Al}_{2} \mathrm{O}_{3}$ coated carbide tool is used as a cutting tool for turning operation. The ANOVA analysis is used to measure the performance quality and mathematical model is developed. The values of probability $>(F)$ is less than 0.05 indicates, the model conditions are significant. The cutting speed is the most influencing parameters compared to other parameters. For the optimum machining parameters leading to temperature rise, the Artificial Neural Network (ANN) model is trained and tested using MAT Lab software. The ANN recommends best minimum predicted value of temperature rise. The confirmatory analysis results, the predicted values were found to be in commendable agreement with the experimental values.
\end{abstract}

Keywords

aluminium-6061, machining parameter, Artificial Neural Network (ANN), Response Surface Methodology (RSM), temperature rise

\section{Introduction}

Nowadays manufacturing industries are concentrating more on optimization techniques in metal cutting process in order to achieve higher production and quality of product as per the customer requirements. Selection of metal cutting process and process parameter is a basic fundamental means for constant enhancement and to produce excellent products [1]. Recent days, many researchers conducted the experimental work to select the optimal cutting parameters to predict temperature rise, surface roughness, tool wear, chip morphology, stress etc. The tool wear and surface finish waviness occurred, when cutting force and vibration of the machine is increased. Increase in temperature during machining results, decrease in dimension accuracy, production efficiency and product quality. The experiment is conducted by the researcher to minimize flank wear, surface finish and cutting zone temperature. By considering cutting speed rate of feed and cutting depth as input response, the experiments are designed using Design of Experiments (DoE) and ANN technique [2]. An experimental investigation is done to predict the temperature rise in cutting tool zone, work piece chip, break of the geometry of tool and cutting force [3]. An attempt is made to compare the influence of process parameters in turning operation using MQL techniques, in order to increase cutting tool life and to improve the quality of the turned workpiece. Cutting force is an important phenomenon in metal cutting operation. When the cutting force increases the cutting temperature of the work piece and tool also increases [4]. The experiment is conducted using aluminium-6061-T6 alloy material in dry turning operation to predict surface roughness. The effect of the machining parameters is determined by using RSM [5]. The researcher [6] proposed a Taguchi optimization technique to study the effect of surface roughness and cutting temperature on face milling using $\mathrm{AlMg}_{3}$ material. The author suggested that the cutting speed is a foremost factor compared to other parameters. The increase in tool wear and surface roughness is caused due to the poor selection of machining parameters. The author conducted an experiment using hardened AISI 4340 steel and suggests that the cutting speed increases, the temperature of the cutting tool also increases [7]. An [8] experiment 
is done using a minimum quality lubrication technique during the turning of AISI 1040 steel. To predict temperature rise, the experiment is performed and compared with dry machining and MQL technique. The author proposes that the minimum temperature be achieved in MQL technique. The experiment [9] is performed using hardened AISI 52100 steel, results the large nose radius of the tool is an important parameter to achieve a better surface finish. The variation of the nose radius during machining of inconel 718 is analyzed at ambient and high temperature taking into account forces, temperature and stresses as an important parameter. Optimization is accomplished through FEM analysis [10]. The author reviews the cutting temperature literature and suggests that the toolwork thermocouple is the best method to determine the temperature increase [11]. An experimental and theoretical study is carried out to measure temperature on the machined surface considering the speed, rate of feed and nose radius of the tool. The author suggests that the radius of the nose slightly influences the surface roughness [12].

A study is conducted on inconel material 718 to measure the effect of the nose radius, resulting in an increase in cutting temperaturedue to the friction of material and tool during machining [13]. The researchers conduct a lot of research in the field of metal cutting using different materials, cutting tools, varying cutting parameters such as spindle speed, cutting speed, feed rate, depth of cut, the angle of the tool such as rake angle, nose radius etc. But there is limited research available by considering aluminium-6061 as workpiece material. Aluminium-6061 material have good strength, excellent corrosion resistance, better weld ability and formability. It is used in building, structural and automotive applications.

\section{Temperature measurements}

During machining, the tool and the workpiece are subjected to heat due to friction between matting parts. The heat generated in both the areas of tool and workpiece causes a major problem like wear in tool, surface irregularity etc. Nowadays, numerous methods are adopted to measure the temperature of tool and workpiece during the machining. Thermocouple [14-16], Infrared thermography [17, 18], Pyrometers [19, 20] Temperature sensors [21]. Finite difference method is used to predict the temperature for both cutting tool and chip break off [22]. An experiment is carried out to measure the difference in cutting temperature under dry and lubrication conditions, suggesting that cutting speed is a predominant factor in relation to other factors [23].

\section{Experimental design}

Owing to the extremely high experimental costs, the number of experiments is minimized by the use of Central Composite Design (CCD) [24]. A design matrix is developed by means of the central composite design method of RSM. Central Composite Design is a factor design consisting of center and star points [25]. Cutting speed, feed rate, depth of cut, and nose radius are selected and its ranges are identified by using the ASM hand book. The upper limit (+2) and lower limit (-2) levels of all the four variables and intermediate levels of 0 , as indicated in Table 1. The experiments are performed in accordance with the CCD, which consists of 30 tests in the form of coded conditions, as shown in Table 2. The temperature of the tool is the output response.

\subsection{Experimentation}

The series of experiments is carried out in a XLTURN$\mathrm{CNC}$ lathe as shown in Fig. 1. Aluminium-6061 is used as a working material and its hardness is valued at 43 HRC. The chemical composition of the workpiece material is reported in Table 3. The workpiece materials are utilized and are used in rare applications in the field of engineering. The $40 \mathrm{~mm}$ diameter and $100 \mathrm{~mm}$ long test samples shall be collected for experimental purposes. The experiments are conducted in dry condition by using $\mathrm{Al}_{2} \mathrm{O}_{3}$ coated carbide tool. Cutting speed, feed rate, depth of cut and nose radius is considered as machining parameter. Hole A1- $\mathrm{mm}$ is drilled into the workpiece sample $\mathrm{mm}$ below the machining surface and the temperature is 10 measured using a $K$-type thermocouple and the observations are tabulated in Table 2.

\subsection{Response surface model for the prediction of temperature}

The author [26] explains the relation between the $y$ response area and the $x$ process variable for a common form of a quadratic polynomial and is given by:

$$
\begin{aligned}
& Y=\beta 0+\beta 1 \times 1+\beta 2 \times 2+\beta 3 \times 3+\beta 11 \times 12+\beta 22 \times 22 \\
& +\beta 12 \times 1
\end{aligned}
$$

Table 1 Process parameters and their levels

\begin{tabular}{llcccccc}
\hline \multirow{2}{*}{ S1. } & Cutting & Unit & \multicolumn{5}{c}{ Factorial Levels } \\
No & parameters & & -2 & -1 & 0 & 1 & 2 \\
\hline 1 & Cutting speed $\left(v_{c}\right)$ & $\mathrm{m} / \mathrm{min}$ & 75 & 90 & 105 & 120 & 130 \\
2 & Feed rate $\left(f_{z}\right)$ & $\mathrm{mm} / \mathrm{rev}$ & 0.09 & 0.18 & 0.27 & 0.36 & 0.45 \\
3 & Depth of cut $\left(a_{p}\right)$ & $\mathrm{mm}$ & 0 & 0.2 & 0.4 & 0.6 & 0.8 \\
4 & Nose radius $\left(r_{n}\right)$ & $\mathrm{mm}$ & 0.2 & 0.4 & 0.6 & 0.8 & 1 \\
\hline
\end{tabular}


Table 2 Experimental values with responses

\begin{tabular}{|c|c|c|c|c|c|c|c|}
\hline S1.No & $\begin{array}{l}\text { Cutting speed } \\
(\mathrm{m} / \mathrm{min})\end{array}$ & $\begin{array}{l}\text { Feed rate } \\
(\mathrm{mm} / \mathrm{rev})\end{array}$ & $\begin{array}{l}\text { Depth of cut } \\
(\mathrm{mm})\end{array}$ & $\begin{array}{l}\text { Nose radius } \\
(\mathrm{mm})\end{array}$ & $\begin{array}{c}\text { Temperature rise } \\
{ }^{\circ} \mathrm{C}-T o \\
\text { (observed) }\end{array}$ & $\begin{array}{c}\text { Temperature rise } \\
{ }^{\circ} \mathrm{C}-T p \\
\text { (Predicted by RSM) }\end{array}$ & $\begin{array}{c}\text { Temperature rise } \\
{ }^{\circ} \mathrm{C}-T p \\
\text { (Predicted by ANN) }\end{array}$ \\
\hline 1 & 120 & 0.36 & 0.6 & 0.4 & 28.8 & 28.800 & 28.7203 \\
\hline 2 & 90 & 0.18 & 0.6 & 0.4 & 29.8 & 29.850 & 30.2870 \\
\hline 3 & 105 & 0.27 & 0.8 & 0.6 & 26.6 & 26.490 & 26.9952 \\
\hline 4 & 105 & 0.27 & 0.4 & 0.6 & 25.8 & 26.100 & 26.1770 \\
\hline 5 & 90 & 0.36 & 0.6 & 0.8 & 24.9 & 24.680 & 25.7842 \\
\hline 6 & 105 & 0.27 & 0.4 & 0.2 & 26.8 & 26.830 & 27.1534 \\
\hline 7 & 120 & 0.36 & 0.6 & 0.8 & 29.7 & 30.110 & 29.7451 \\
\hline 8 & 105 & 0.27 & 0.4 & 0.6 & 28.2 & 26.100 & 26.1770 \\
\hline 9 & 75 & 0.27 & 0.4 & 0.6 & 29.3 & 29.610 & 29.4078 \\
\hline 10 & 90 & 0.18 & 0.2 & 0.4 & 27.1 & 26.800 & 26.8561 \\
\hline 11 & 90 & 0.36 & 0.6 & 0.4 & 28.6 & 28.560 & 27.8824 \\
\hline 12 & 105 & 0.27 & 0.4 & 0.6 & 25.6 & 26.100 & 26.1770 \\
\hline 13 & 105 & 0.27 & 0 & 0.6 & 29.6 & 29.690 & 28.9326 \\
\hline 14 & 120 & 0.18 & 0.6 & 0.8 & 29.8 & 29.750 & 30.0727 \\
\hline 15 & 120 & 0.18 & 0.2 & 0.4 & 30.1 & 30.230 & 30.1921 \\
\hline 16 & 105 & 0.27 & 0.4 & 0.6 & 25.6 & 26.100 & 26.1770 \\
\hline 17 & 90 & 0.36 & 0.2 & 0.8 & 27.8 & 27.830 & 27.3538 \\
\hline 18 & 90 & 0.36 & 0.2 & 0.4 & 27.2 & 27.160 & 27.3734 \\
\hline 19 & 105 & 0.27 & 0.4 & 1 & 27.1 & 27.060 & 27.2988 \\
\hline 20 & 120 & 0.18 & 0.2 & 0.8 & 34.2 & 34.350 & 35.0518 \\
\hline 21 & 90 & 0.18 & 0.2 & 0.8 & 25.8 & 25.710 & 25.6116 \\
\hline 22 & 105 & 0.45 & 0.4 & 0.6 & 27.6 & 27.560 & 27.4705 \\
\hline 23 & 105 & 0.09 & 0.4 & 0.6 & 26.8 & 26.830 & 27.0262 \\
\hline 24 & 120 & 0.36 & 0.2 & 0.4 & 30.4 & 30.500 & 31.0221 \\
\hline 25 & 105 & 0.27 & 0.4 & 0.6 & 25.8 & 26.100 & 26.1770 \\
\hline 26 & 120 & 0.18 & 0.6 & 0.4 & 30.1 & 30.180 & 27.5176 \\
\hline 27 & 135 & 0.27 & 0.4 & 0.6 & 38.8 & 38.480 & 37.4069 \\
\hline 28 & 90 & 0.18 & 0.6 & 0.8 & 24.2 & 24.210 & 25.0425 \\
\hline 29 & 120 & 0.36 & 0.2 & 0.8 & 36.5 & 36.360 & 35.8257 \\
\hline 30 & 105 & 0.27 & 0.4 & 0.6 & 25.6 & 26.100 & 26.1770 \\
\hline
\end{tabular}

where:

- $\beta 0$ is a constant,

- $\beta 1, \beta 2, \beta 3$ is the linear term coefficient,

- $\beta 11, \beta 22$ is the quadratic term coefficient and

- $\beta 12$ is the interaction term coefficient.

DESIGN EXPERT V12 software is used for the analysis purpose [27]. The second-order quadratic model is designed to predict the increase in temperature. The model is verified for its competence using analysis of variance (ANOVA). Table 4 shows the ANOVA analysis for the prediction of temperature. The objective of ANOVA is to specify the magnitude associated with each element in the target operation and to reduce the error. ANOVA is a technique used to select the highest quality components from a large selection of options. ANOVA is used to identify which actual measurements affect the specified values [28].

The model F-value of 55.14 implies the model is significant. There is only a $0.01 \%$ chance that an $F$-value this large occurs due to noise.

$P$-values less than $5 \%$ indicate that the model terms are significant. In this case $v_{c}, a_{p}, v_{c} a_{p}, v_{c} r_{n}, f_{z} C, f_{z} r_{n}, a_{p} r_{n}, v_{c}^{2}$, $f_{z}^{2}, a_{p}^{2}$ are significant model terms. The values greater than 0.1000 indicates the model terms are not significant.

The Lack of fit F-value of 0.06 implies the lack of fit is not significant relative to the pure error. There is a $99.99 \%$ probability that a lack of adjustment of this $F$-value will occur due to noise. Non-significant lack of fit is good for experimentation purpose. 


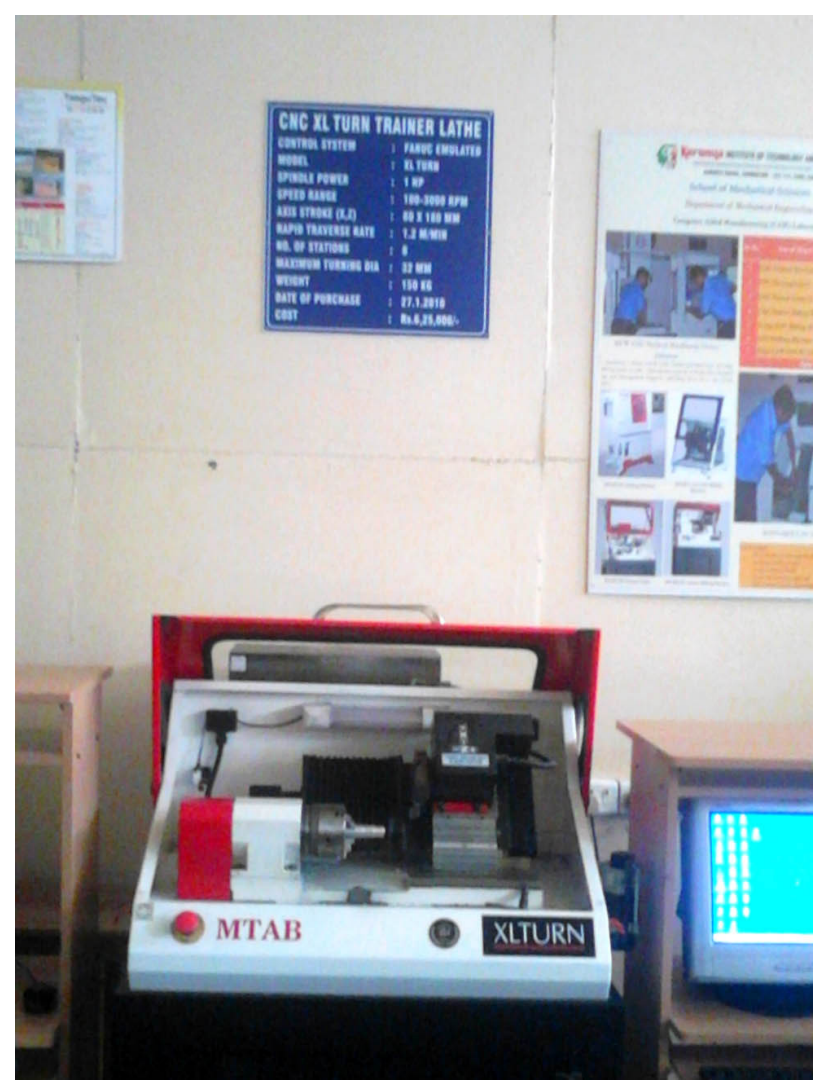

Fig. 1 Experimental set up using XLTURN-CNC lathe
The regression equation (Eq. (2)) obtained by using design software is:

Temperature rise $\left(T_{m}\right)=+125.64792-1.85694 \times v_{c}$

$-19.62963 \times f_{z}+36.41667 \times a_{p}-46.70833 \times r_{n}$

$-0.018519 \times v_{c} \times f_{z}-0.258333 \times v_{c} \times a_{p}$

$+0.433333 \times v_{c} \times r_{n}-22.91667 \times f_{z} \times a_{p}$

$+24.30556 \times f_{z} \times r_{n}-28.43750 \times a_{p} \times r_{n}$

$+0.008824 \times v_{c}^{2}+33.69342 \times f_{z}^{2}+12.44792 \times a_{p}^{2}$

$+5.26042 \times r_{n}^{2}$.

The calculated value of the $F$ value is more than the standard (tabulated) value of the $F$ value for temperature rise is shown in the Table 4; the model is adequate for a desired $95 \%$ level of confidence. The error found between the experimental and predicted values is acceptable level.

\section{Results and discussions}

\subsection{Interaction effect}

Figs. 2 to 5 shows the interaction effect of the machining parameters on the temperature rise.

In Fig. 2 depicts the interaction result between cutting speed over feed rate. The cutting speed plays a major

Table 3 Chemical composition for aluminium-6061

\begin{tabular}{lccccccccc}
\hline Al 6061 & $\mathrm{Al}$ & $\mathrm{Si}$ & $\mathrm{Fe}$ & $\mathrm{Cu}$ & $\mathrm{Mn}$ & $\mathrm{Mg}$ & $\mathrm{Cr}$ & $\mathrm{Zn}$ \\
\hline Weight $(\%)$ & $\mathrm{Bal}$ & $0.40-0.80$ & $0.70 \max$ & $0.15-0.40$ & 0.15 & $0.8-1.2$ & $0.04-0.35$ & 0.25 max & 0.15 max \\
\hline
\end{tabular}

Table 4 ANOVA Table for prediction of temperature rise

\begin{tabular}{|c|c|c|c|c|c|c|}
\hline Source & Sum of squares & $d f$ & Mean square & $F$-value & $p$-value & \\
\hline Model & 307.03 & 14 & 21.93 & 55.14 & $<0.0001$ & Significant \\
\hline$v_{c}$ - cutting Speed & 117.93 & 1 & 117.93 & 296.51 & $<0.0001$ & \\
\hline$f_{z}$ - feed Rate & 0.8067 & 1 & 0.8067 & 2.03 & 0.1749 & \\
\hline$a_{p}-$ depth of Cut & 15.36 & 1 & 15.36 & 38.62 & $<0.0001$ & \\
\hline$r_{n}-$ nose Radius & 0.0817 & 1 & 0.0817 & 0.2053 & 0.6569 & \\
\hline$v_{c} f_{z}$ & 0.01 & 1 & 0.01 & 0.0251 & 0.8761 & \\
\hline$v_{c} a_{p}$ & 9.61 & 1 & 9.61 & 24.16 & 0.0002 & \\
\hline$v_{c} r_{n}$ & 27.04 & 1 & 27.04 & 67.99 & $<0.0001$ & \\
\hline$f_{z} a_{p}$ & 2.72 & 1 & 2.72 & 6.85 & 0.0195 & \\
\hline$f_{z} r_{n}$ & 3.06 & 1 & 3.06 & 7.7 & 0.0142 & \\
\hline$a_{p} r_{n}$ & 20.7 & 1 & 20.7 & 52.05 & $<0.0001$ & \\
\hline$v_{c}^{2}$ & 108.12 & 1 & 108.12 & 271.85 & $<0.0001$ & \\
\hline$f_{z}^{2}$ & 2.04 & 1 & 2.04 & 5.14 & 0.0386 & \\
\hline$a_{p}^{2}$ & 6.8 & 1 & 6.8 & 17.1 & 0.0009 & \\
\hline$r_{n}^{2}$ & 1.21 & 1 & 1.21 & 3.05 & 0.101 & \\
\hline Residual & 5.97 & 15 & 0.3977 & & & \\
\hline Lack of fit & 0.6258 & 10 & 0.0626 & 0.0586 & 0.9999 & Not significant \\
\hline Pure error & 5.34 & 5 & 1.07 & & & \\
\hline Cor total & 313 & 29 & & & & \\
\hline
\end{tabular}



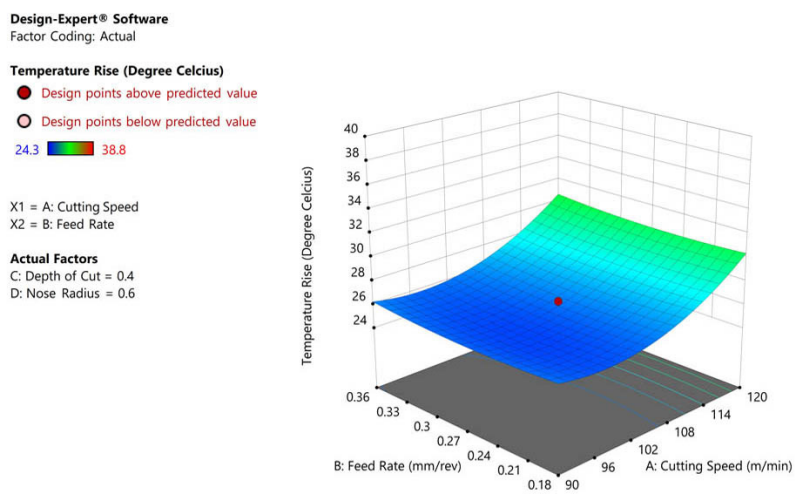

Fig. 2 Interaction effect of cutting speed and feedrate over temperature rise
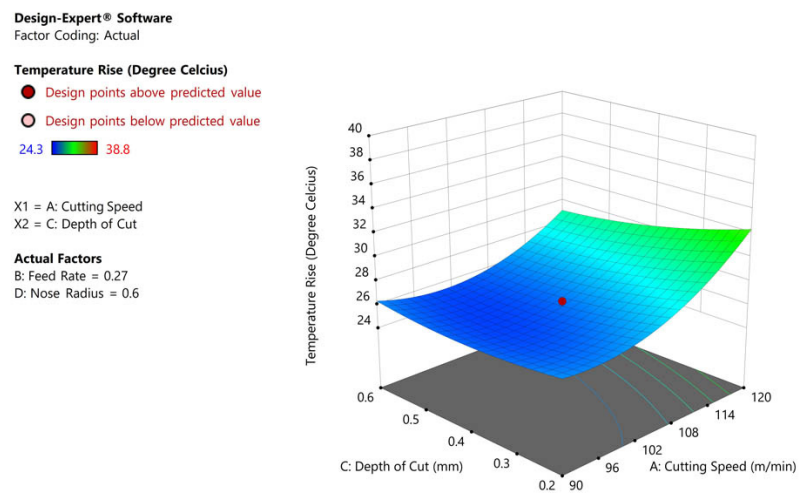

Fig. 3 Interaction effect of cutting speed and depth of cutover temperature rise
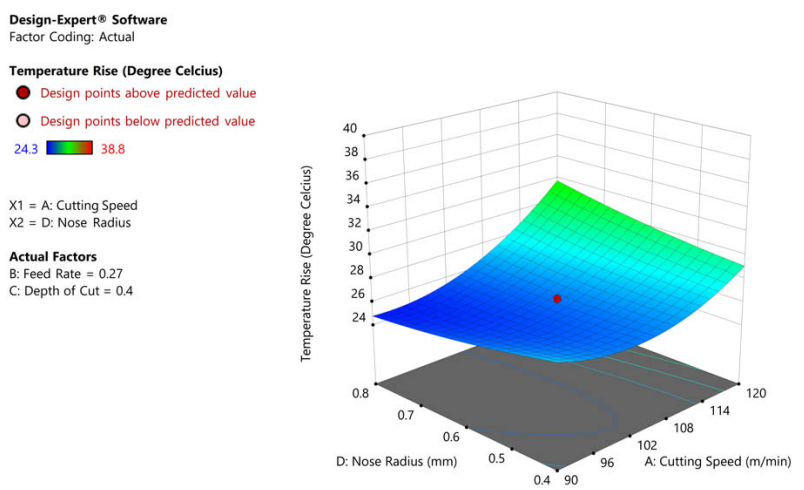

Fig. 4 Interaction effect of nose radius and cutting speed over temperature rise

role in increasing the temperature, so the impact is more as shown in the figure in relation to the feed rate. When the cutting speed increases, the temperature also increases. It is evident from the Fig. 2 that the value of minimum temperature attained in between $91 \mathrm{~m} / \mathrm{min}$ to $102 \mathrm{~m} / \mathrm{min}$.

This is caused by the plastic deformation and friction of the tool and workpiece. The heat developed in the cutting area causes a high temperature increase due to the
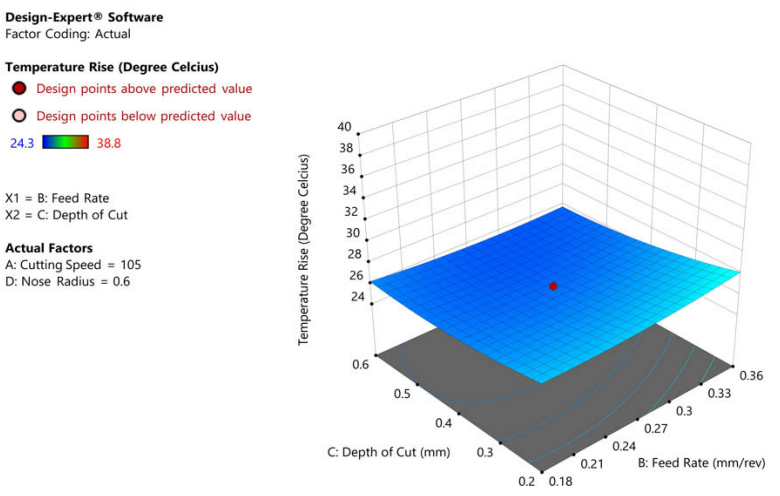

Fig. 5 Interaction effect of feed rate and depth of cutover temperature rise

automatic diffusion between the tool and the workpiece material, which propagates the wear of the tool. The findings are verified from the ANOVA table.

Fig. 3 evidenced that the cutting depth to the temperature rise has a less significant effect. The Fig. 3 illustrates that there is a subsequent increase in the depth of cut, a slight increase in temperature. If there is an increase in the cutting depth, the greater quantity of material is removed, the results increase the cutting temperature. At lower depths of cut, less amount of workpiece material adhere on the flank of the tool than at larger depth of the cut. This adhesion of workpiece material on the tool flank causes an increase in temperature rise. The findings are verified from the ANOVA table.

Fig. 4 depicts the interaction and effect of nose radius on temperature rise. It proves that the nose radius on the temperature rise of the turning process has a significant effect. The Fig. 4 illustrates that the increase in the nose radius reduces the increase in temperature. The findings were also verified using the ANOVA table. However, the increase in the nose radius translates into an increase in the length of the active part of the cutting edge and the mass of the tool point.

Fig. 5 shows that there is an increase in cutting speed and depth of cut as the temperature of the turning process increases slightly and has a less significant impact. Fig. 6 shows the relationship between predicted to actual values.

\section{Artificial neural network}

The artificial neural network can replicate a number of functions of human behavior, which are formed by a limited number of layers with various computational elements called neurons [29]. ANN is an adaptive arrangement which alters its arrangement based on external or internal information circulating throughout the network. ANN is working on the learning algorithm. It is divided into supervised 

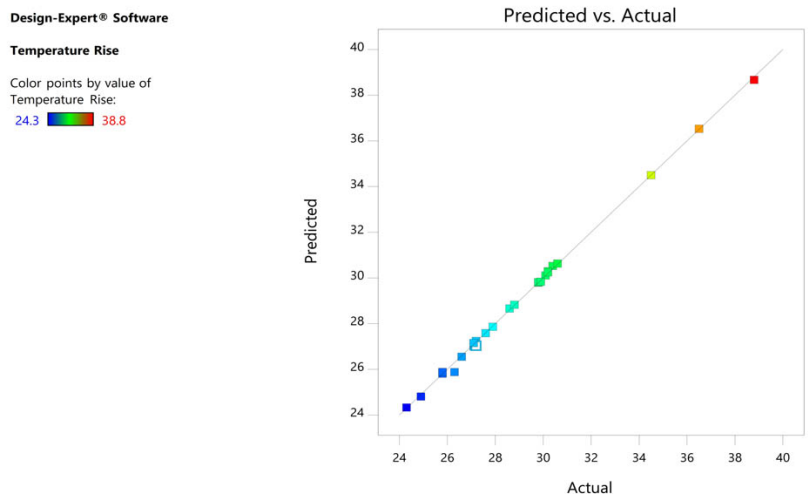

Fig. 6 Relationship between predicted to actual values.

and unsupervised learning. In supervised, the input and output are trained by using the data. In unsupervised mode, output data is not available, new input data called cluster and input data must be entered, ANN data can be assigned in a corresponding cluster [30]. The ANN structure of cutting parameter is shown in Fig. 7. The ANN architecture, the result is to predict the temperature rise $(T m)$. The network contains three layers: input, hidden, and output layers. The input and output layers in the form of nodes and the hidden layer provide a relation between the input layers and the output layers. The number of neurons in the input layer and the output layer is based on the geometry of the ANN architecture layer of the problem. The optimum values of network parameter are shown in Table 5.

The input layer which receives four neurons and the output layer have one neuron. However, there is no common rule to select the number of neurons in a hidden layer and the number of hidden layers [31]. The processing neuron of the hidden layer provides the processed data of the neurons of the input layers to the neurons of the output layer [32]. The neural network method known as the back-propagation neural network algorithm is used in the study. To train the neural network, the cutting speed,

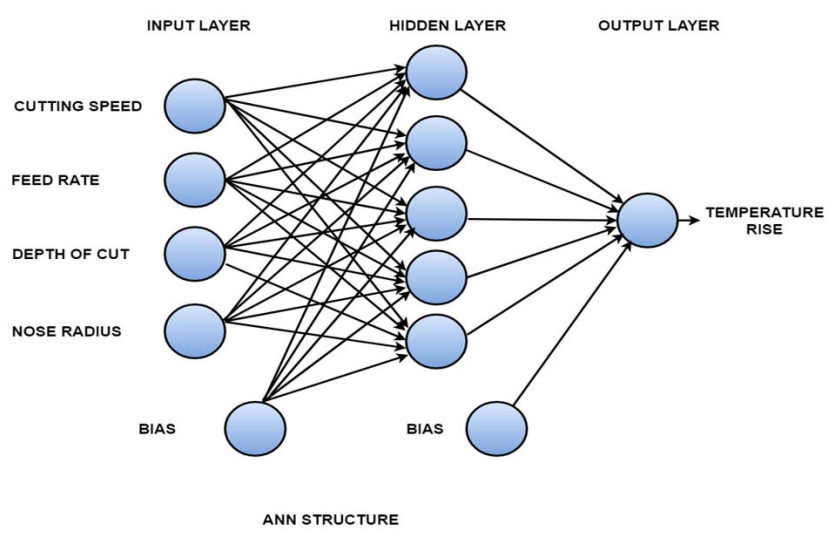

Fig. 7 ANN Structure of Cutting parameter
Table 5 Optimum values of network parameter

\begin{tabular}{llc}
\hline Sl.No & Parameter & Values \\
\hline 1 & Number of input layer & 1 \\
2 & Number of input layer unit & 4 \\
3 & Number of Hidden layer & 1 \\
4 & Number of Hidden layer unit & 5 \\
5 & Number of output layer & 1 \\
6 & Number of output layer unit & 1 \\
7 & Number of Epochs & 1000 \\
8 & Algorithm & Back propagation \\
9 & Learning rule & Gradient descent rule \\
\hline
\end{tabular}

feed rate, depth of cut and nose radius are used as input parameters, and the temperature as the output parameter. The ANN cutting parameter structure is shown in Fig. 7. Fig. 8 shows the neural network trainer in which 1000 iterations are performed for temperature prediction. Fig. 9 shows the validation performance between experimental, training, predicted value. The best ANN result and response to errors after 1000 epochs. Fig. 10 shows the Plot Regression of training and validation data. From the

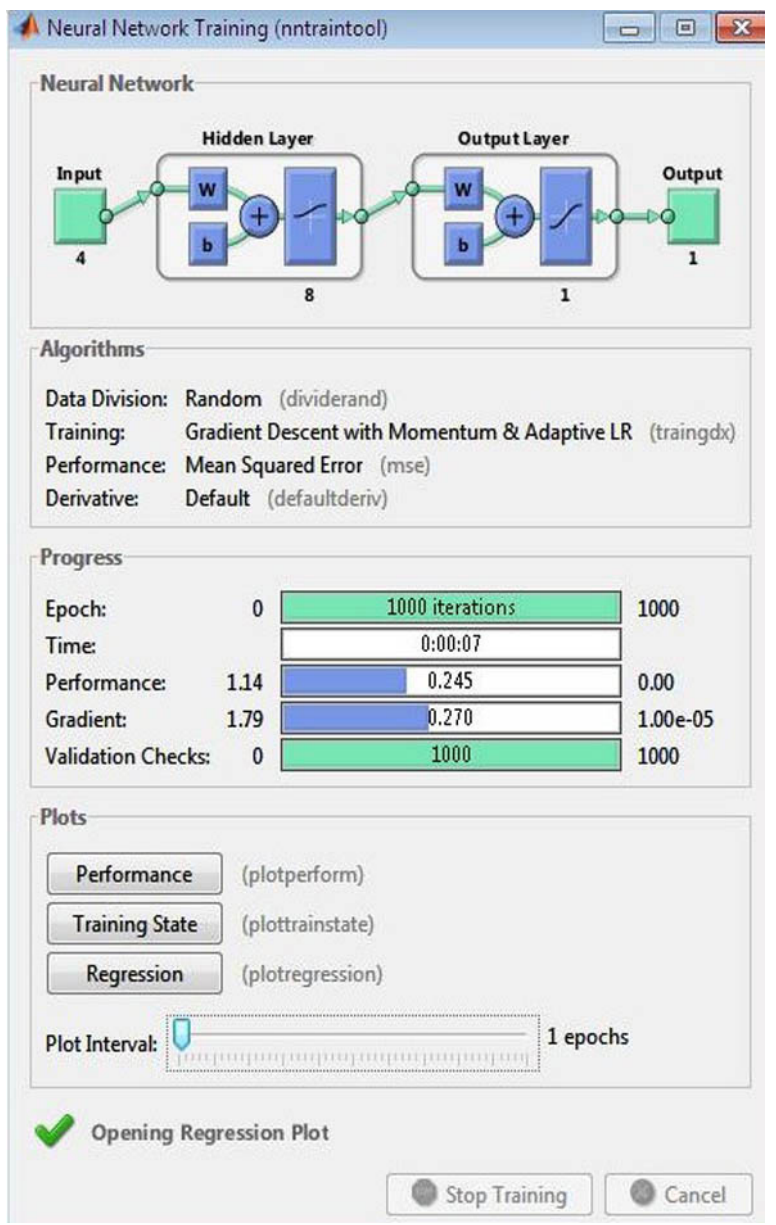

Fig. 8 Neural network training 


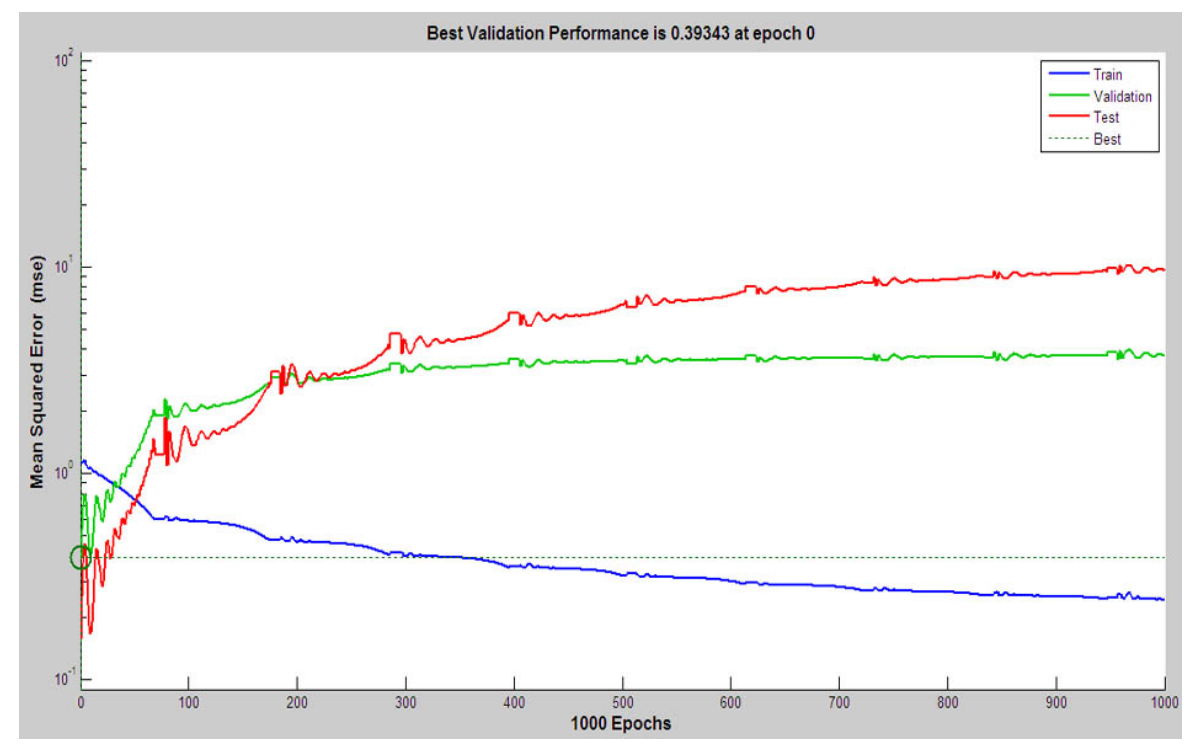

Fig. 9 ANN validation performance
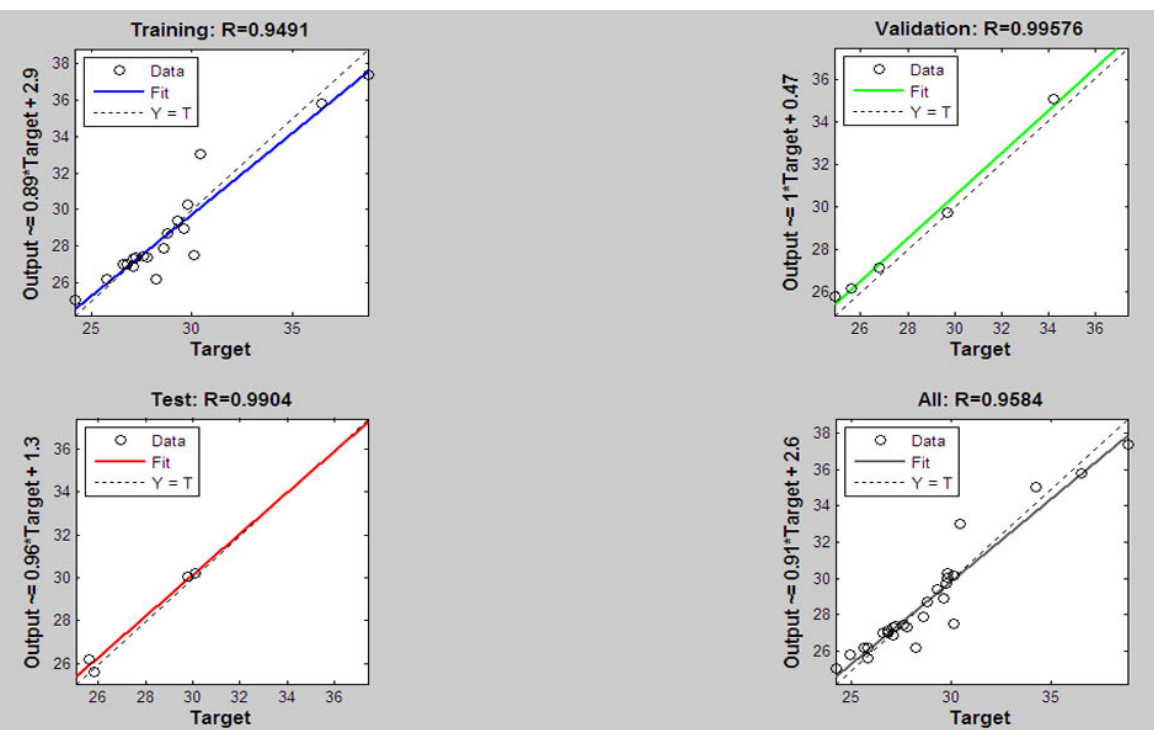

Fig. 10 Plot regression

30 datasets obtained from the experiment, 20 datasets are randomly selected to form the ANN model. To test the ANN model, ten datasets are chosen. The results predicted by ANN model are compared with experimental values and the percentage of errors is tabulated in Table 6 . From Table 6, it is clear that the developed model is well trained using ANN and has the capability to predict the new outcome result. The average prediction error for the data set is found to be $0.84 \%$ and maximum prediction error is $9.675262 \%$. The graph in Fig. 11 shows the comparison between the trained ANN output and experimental data. The graph in Fig. 12 illustrates the comparison of experimental data, RSM and ANN data sets. The results indicate a good agreement between the experimental data predicted by the RSM and predicted by the ANN.

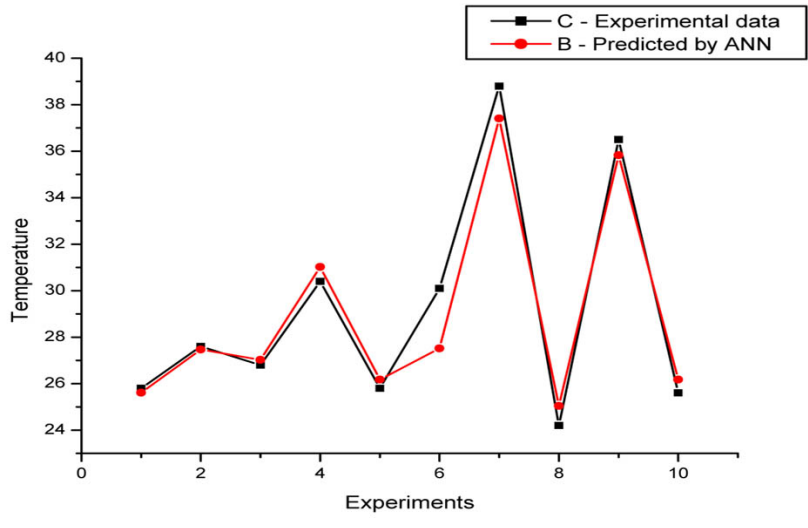

Fig. 11 Comparison of output of trained ANN and experimental data

The graph in Fig. 13 shows the percentage of errors comparison between RSM and ANN. 


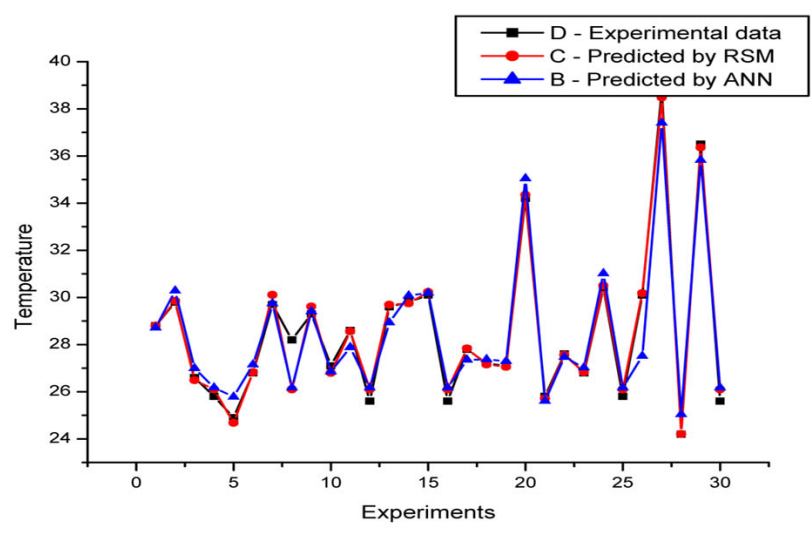

Fig. 12 Comparison of experimental, RSM and ANN data

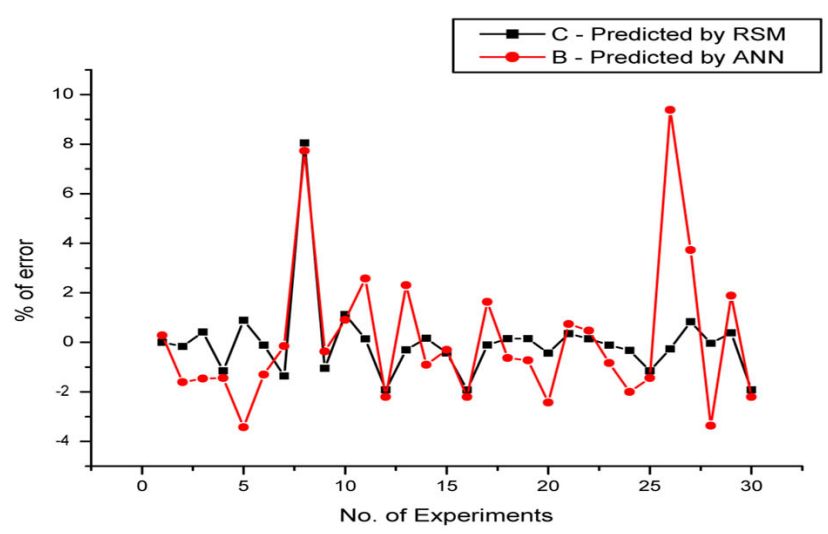

Fig. 13 Comparison of errors - RSM and ANN

\section{Comparative study}

The findings of the developed ANN model were compared with similar studies in the literature. The experiment is conducted by the researcher using aluminum-6061 to predict temperature increase using RSM (DoE technique) and genetic algorithm. The parameters taken into account for the turning operation are the cutting speed, feed rate, depth of cut and nose radius. The author suggests that cutting speed is the most influential parameter in comparison with other parameters [33].

\section{Conclusion}

A second order mathematical model is developed using CCD by Response Surface Methodology (RSM) of DoE

\section{References}

[1] Das, P. P., Diyaley, S., Chakraborty, S., Ghadai, R. K. "MultiObjective Optimization of Wire Electro Discharge Machining (WEDM) Process Parameters Using Grey-Fuzzy Approach", Periodica Polytechnica Mechanical Engineering, 63(1), pp. 16-25, 2019.

https://doi.org/10.3311/PPme.12167 is developed to predict the temperature rise using aluminium-6061 as workpiece material by considering cutting speed, feed rate, depth of cut and nose radius as input parameters. The interaction effect of the process parameter is studied by using RSM. The optimization was carried out by using an Artificial Neural Network (ANN). Analysis of the ANN model reveals improved prediction data.

The validation analysis showed in Table 2 that the expected RSM and ANN values were close to the validation values, while the ANN values showed the lowest deviation than RSM values. This finding suggests that the ANN has shown better prediction and adjustment capacity in comparison with the RSM:

- The cutting speed is the most important influencing parameter with respect to the other parameters. The temperature is low between $91 \mathrm{~m} / \mathrm{min}$ and $102 \mathrm{~m} / \mathrm{min}$ of cutting speed.

- The nose radius of cutting tool should be $0.6 \mathrm{~mm}$ to $0.8 \mathrm{~mm}$ for the better minimum temperature value.

- The optimization using ANN shows a good agreement between the observed values and predicted by ANN.

- The percentage of error in ANN predicted data is less than $5 \%$. So the model is acceptable.

- The predictive ANN model is found to be accomplished for the better predictions of temperature rise.

\subsection{Future studies}

There is a lot of research opportunities available using aluminium-6061 material:

- The experiment needs to be carried out in the future to find the effect of cutting fluids, MQL, cryogenic machining.

- Modifying the tool nomenclature to ensure high quality machining.

- There is a limited research available to optimize machinability, Impact toughness, material removal rate, chip volume ratio, surface integrity etc.

- Sustainable machining technologies can be implemented in the future to avoid environmental pollution.

[2] Choudhury, S. K., Bartarya, G. "Role of temperature and surface finish in predicting tool wear using neural network and design of experiments", International Journal of Machine Tools and Manufacturing, 43(7), pp. 747-753, 2003. https://doi.org/10.1016/S0890-6955(02)00166-9 
[3] Oxley, P. L. B., Shaw, M. C. "Mechanics of Machining: An Analytical Approach to Assessing Machinability", Journal of Applied Mechanics, 57(1), p. 253, 1990.

https://doi.org/10.1115/1.2888318

[4] Hadad, M., Sadeghi, B. "Minimum quantity lubrication-MQL turning of AISI 4140 steel alloy", Journal of Cleaner Production, 54, pp. 332-343, 2013.

https://doi.org/10.1016/j.jclepro.2013.05.011

[5] Sumesh, C. S., Ramesh, A. "Numerical Modelling and Optimization of Dry Orthogonal Turning of AI6061 T6 Alloy", Periodica Polytechnica Mechanical Engineering, 62(3), pp. 196-202, 2018. https://doi.org/10.3311/PPme.11347

[6] Fratila, D., Caizar, C. "Application of Taguchi method to selection of optimal lubrication and cutting conditions in face milling of AlMg ${ }_{3}$ ", Journal of Cleaner Production, 19(6-7), pp. 640-645, 2011. https://doi.org/10.1016/j.jclepro.2010.12.007

[7] Suresh, R., Basavarajappa, S., Gaitonde, V. N., Samuel, G. L. "Machinability investigations on hardened AISI 4340 steel using coated carbide insert", International Journal of Refractory Metals and Hard Materials, 33, pp. 75-86, 2012.

https://doi.org/10.1016/j.ijrmhm.2012.02.019

[8] Dhar, N. R., Islam, M. W., Islam, S., Mithu, M. A. H. "The influence of minimum quantity of lubrication (MQL) on cutting temperature, chip and dimensional accuracy in turning AISI-1040 steel", Journal of Material Processing Technology, 171(1), pp. 93-99, 2006. https://doi.org/10.1016/j.jmatprotec.2005.06.047

[9] Chou, K. Y., Song, H. "Tool nose radius effects on finish hard turning", Journal of Materials Processing Technology, 148(2), pp. 259-268, 2004.

https://doi.org/10.1016/j.jmatprotec.2003.10.029

[10] Parida, A. K., Maity, K. "Effect of nose radius on forces, and process parameters in hot machining of Inconel 718 using finite element analysis", Engineering Science and Technology, an International Journal, 20(2), pp. 687-693, 2017. https://doi.org/10.1016/j.jestch.2016.10.006

[11] da Silva, M. B., Wallbank, J. "Cutting temperature: Prediction and measurement methods - a review", Journal of Materials Processing Technology, 88(1-3), pp. 195-202, 1999. https://doi.org/10.1016/S0924-0136(98)00395-1

[12] Kimakh, K., Aghzer, S., Chouaf, A., Saoud, A., Mallil, E. H., Chergui, M. "Analytical Model for Predicting Surface Roughness as a Function of AISI 1045 Steel Machining Parameters", International Journal of Modern Manufacturing Technologies, 10(1), pp. 57-62, 2018. [online] Available at: https:/ijmmt.ro/ vol10no12018/08_Khadija_Kimakh.pdf [Accessed: 15 May 2020]

[13] Hua Y., Liu, Z. "Effects of cutting parameters and tool nose radius on surface roughness and work hardening during dry turning Inconel 718", The International Journal of Advanced Manufacturing Technology, 96(5), pp. 2421-2430, 2018. https://doi.org/10.1007/s00170-018-1721-7

[14] Kitagawa, T., Kubo, A., Maekawa, K. "Temperature and wear of cutting tools in high-speed machining of Inconel 718 and Ti-6Al6V-2Sn", Wear, 202(2), pp. 142-148, 1997. https://doi.org/10.1016/S0043-1648(96)07255-99
[15] Weinert, K., Tillmann, W., Hammer, N., Kempmann, C., Vogli, E. "Tool Coatings as Thermocouple for the Monitoring of Temperatures in Turning Processes", Advanced Engineering Materials, 8(10), pp. 1007-1010, 2006. https://doi.org/10.1002/adem.200600122

[16] Komanduri, R., Hou, Z. B. "A Review of the Experimental Technique for the Measurement of Heat and Temperatures Generated in Some Manufacturing Processes and Tribology", Tribology International, 34(10), pp. 653-682, 2001. https://doi.org/10.1016/S0301-679X(01)00068-8

[17] Garcia-Gonzalez, J. C., Moscoso-Kingsley, W., Madhavan, V. "Rake face temperature when machining with coated cutting tools", Procedia Manufacturing, 5, pp. 815-827, 2016. https://doi.org/10.1016/j.promfg.2016.08.066

[18] Lane, B., Whitenton, E., Madhavan, V., Donmez, A. "Uncertainty of temperature measurements by infrared thermography for metal cutting application", Metrologia, 50(6), pp. 637-653, 2013. https://doi.org/10.1088/0026-1394/50/6/637

[19] Sutter, G., Faure, L., Molinari, A., Ranc, N., Pina, V. "An experimental technique for the measurement of temperature fields for the orthogonal cutting in high speed machining", International Journal of Machine Tools and Manufacture, 43(7), pp. 671-678, 2003. https://doi.org/10.1016/S0890-6955(03)00037-3

[20] Abukhshim, N. A., Mativenga, P. T., Sheikh, M. A. "Investigation of heat partition in high speed turning of high strength alloy steel", International Journal of Machine Tools and Manufacture, 45(15), pp. 1687-1695, 2005. https://doi.org/10.1016/j.ijmachtools.2005.03.008

[21] Zhang, Y., Yang, J., Jiang, H. "Machine tool thermal error modeling and prediction by grey neural network", The International Journal of Advanced Manufacturing Technology, 59(9), pp. 1065-1072, 2012. https://doi.org/10.1007/s00170-011-3564-3

[22] Lazoglu, I., Altintas, Y. "Prediction of tool and chip temperature in continuous and interrupted machining", International Journal of Machine Tools and Manufacture, 42(9), pp. 1011-1022, 2002. https://doi.org/10.1016/S0890-6955(02)00039-1

[23] Li, K. M., Liang, S. Y. "Modeling of Cutting Temperature in Near Dry Machining", Journal of Manufacturing Science Engineering, 128(2), pp. 416-424, 2006. https://doi.org/10.1115/1.2162907

[24] Geier, N., Pereszlai, C. "Analysis of characteristics of surface Roughness of Machined CFRP Composites", Periodica Polytechnica Mechanical Engineering, 64(1), pp. 67-80, 2020. https://doi.org/10.3311/PPme.14436

[25] Ribeiro, J., Lopes, H., Queijo, L., Figueiredo, D. "Optimization of Cutting Parameters to Minimize the Surface Roughness in the End Milling Process Using the Taguchi method", Periodica Polytechnica Mechanical Engineering, 61(1), pp. 30-35, 2017. https://doi.org/10.3311/PPme.9114

[26] Mahesh, G., Muthu, S., Devadasan, S. R. "Prediction of surface roughness of end milling operation using genetic algorithm", The International Journal of Advanced Manufacturing Technology, 77(1), pp. 369-381, 2015. https://doi.org/10.1007/s00170-014-6425-z 
[27] StateEase"Design-Expert Version 12",[computerprogram] Available at: https://www.statease.com/ [Accessed: 20 November 2020]

[28] Țîțu, A. M., Sandu, A. V., Pop, A. B., Țîțu, Ș., Frățilă, D. N., Ceocea, C., Boroiu, A. "Design of Experiment in the Milling Process of Aluminum Alloys in the Aerospace Industry", Applied Sciences, 10(19), Article Number: 6951, 2020. https://doi.org/10.3390/app10196951

[29] Asiltürk, I., Çunkas, M. "Modeling and prediction of surface roughness in turning operations using artificial neural network and multiple regression method", Expert System with Applications, 38(5), pp. 5826-5832, 2011.

https://doi.org/10.1016/j.eswa.2010.11.041

[30] Jafarian, F., Taghipour, M., Amirabadi, H. "Application of artificial neural network and optimization algorithms for optimizing surface roughness, tool life and cutting forces in turning operation", Journal of Mechanical Science and Technology, 27(5), pp. 1469-1477, 2013.

https://doi.org/10.1007/s12206-013-0327-0
[31] Pala, M., Caglar, N., Elmas, M., Cevik, A., Saribiyik, M. "Dynamic soil structure interaction analysis of buildings by neural network", Construction and Building Materials, 22(3), pp. 330-342, 2008. https://doi.org/10.1016/j.conbuildmat.2006.08.015

[32] Lin, Y. C., Wu, K. D., Shih, W. C., Hsu, P. K., Hung, J. P. "Prediction of Surface Roughness Based on Cutting Parameters and Machining Vibration in End Milling Using Regression Method and Artificial Neural Network", Applied Sciences, 10(11), Article Number: 3941, 2020. https://doi.org/10.3390/app10113941

[33] Gopal, M. "Optimization of Machining Parameters on Temperature Rise in CNC Turning Process of Aluminium-6061 Using RSM and Genetic Algorithm", International Journal of Modern Manufacturing Technologies, 12(1), pp. 36-43, 2020. [online] Available at: https://ijmmt.ro/vol12no12020/05_Mahesh_Gopal. pdf [Accessed: 24 November 2020] 